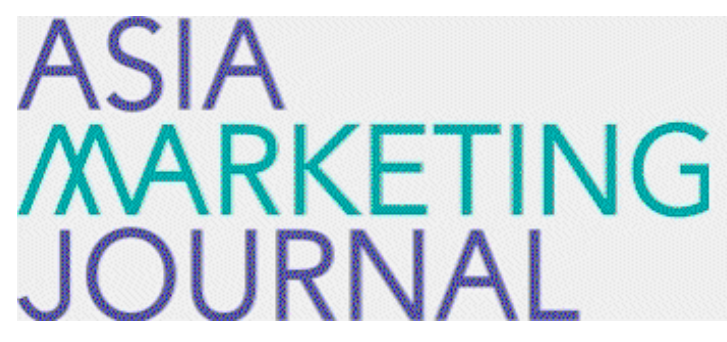

ASIA MARKETING JOURNAL

Volume 18 | Issue 3

Article 3

$10-31-2016$

\title{
The Influence of Love versus Lust on Consumer Judgments
}

Jung-Yun Kang

Young-Jee Han

Follow this and additional works at: https://amj.kma.re.kr/journal

Part of the Marketing Commons

\section{Recommended Citation}

Kang, Jung-Yun and Han, Young-Jee (2016) "The Influence of Love versus Lust on Consumer Judgments," Asia Marketing Journal: Vol. 18 : Iss. 3 , Article 3.

Available at: https://doi.org/10.15830/amj.2016.18.3.35

This Article is brought to you for free and open access by Asia Marketing Journal. It has been accepted for inclusion in Asia Marketing Journal by an authorized editor of Asia Marketing Journal. 


\title{
The Influence of Love versus Lust on Consumer Judgments
}

\author{
Jung-Yun Kang* \\ Young-Jee Han**
}

\begin{abstract}
According to previous literature, love involves a feeling of emotional bonds, attachment, and commitment to a specific target from a long-term perspective. In contrast, lust is defined as a sexual desire to engage in sexual activities from a short-term perspective. This research investigates the influence of feelings of love or lust on consumers' long-term benefit-seeking and risk-taking behaviors. Study 1 examined whether consumers' long-term benefit-seeking behaviors depend on feelings of love or lust. As a result, consumers who experienced feelings of love were more likely to prefer products that provide long-term benefits (e.g., a hybrid car) than those who experienced feelings of lust. Study 2 investigated consumers' risk-taking behaviors, depending on feelings of love or lust. The results showed that consumers in the lust condition were more willing to take a risk (e.g., a trip to a hazardous area) than those in the love condition. Taken together, this research demonstrates that consumers' long-term benefit-seeking and risk-taking behaviors depend on feelings of love or lust. Practical and theoretical implications are further discussed.
\end{abstract}

Key words: Love, Lust, Temporal perspective, Risk-taking, Risky decisions

Love and lust are human instincts. We experience feelings of love and lust every day, but sometimes confuse the two. However, love and lust are clearly distinct emotions. According to previous studies, love is defined as an emotion that accompanies emotional ties, affection and commitment to a specific target in the long term.
On the other hand, lust is defined as a feeling people experience when looking for a sexual partner to engage in sexual activity so as to fulfill sexual needs in the short term (Förster, Özelsel, and Epstude 2010). Furthermore, scientifically, it has been proven that different parts of the human brain respond to feelings of

\footnotetext{
* Doctoral Candidate, School of Business, Sunkyunkwan University (jungyoon13@skku.edu)

** Assistant Professor of Marketing, School of Business, Sunkyunkwan University (yjhan@skku.edu)
} 
love and lust (Cacioppo et al. 2012). Researchers have found that feelings of lust, such as the taste of food and sex, stimulate the "instinctive pleasure" part of the striatum, whereas the "rational pleasure" region of the striatum is in charge of so-called "valuable love," such as conjugal love or family affection. Thus, love and lust are the result of completely different brain stimulations.

Although love and lust - two distinctly independent emotions - are basic emotions that cannot be separated from every aspect of human life, prior studies have mainly focused on emotional impact or sexual desire within interpersonal relations (Diamond, 2004; Epstude and Förster, 2011; Fisher and Byrne, 1978). This research aims to look into the impact of love and lust on consumer purchasing behavior, beyond interpersonal strategies.

In specific, we verify whether consumers with strong sentiments of love or lust show different purchasing behavior in seeking long-term benefit. According to previous studies, love can be associated with "foreverness," or long-term involvement (Mikulincer 1998; Mikulincer and Shaver 2007), whereas lust is a momentary feeling not accompanied by a long-term perspective (Sprecher and Regan 1998). Therefore, we expect that the consumers who have experienced love, compared to those who have experienced lust, will favor products with long-term benefits (e.g., hybrid vehicles), although it may bring loss in the short term. We also examine consumers' risk-taking behaviors, depending on the psychological state of love and lust. In considering the fact that the purpose of love is to feel emotional attachment and to share life with a specific subject (Mikulincer 1998; Mikulincer and Shaver 2007), while lust is often expressed in behaviors such as one-night stands with a stranger to satisfy desires (Sprecher and Regan 1998), actions to satisfy sexual desires accompany risk, to some extent. In other words, given differential foci on future between love and lust, lust may generate long-term loss for temporary benefit. Therefore, we predict that consumers who experience love compared to lust will tend to take a higher level of risk (e.g. travel to dangerous areas). We provide ways to increase the effectiveness of marketing communications via message differentiation, taking into account product attributes and purchasing situations.

\section{Theoretical Background}

\subsection{Love, Lust and Temporal Perspective}

Love and lust are essentially independent concepts related to distinctly separate neural biological material (Diamond 2003, 2004). Love is an emotional state of not wanting to be separated from one another, which begins from emotional attachments between a mother and her babies 
and evolves into a strong attachment to an intimate partner. On the other hand, lust is an emotional state of longing for sexual activity for the purpose of reproduction (Aron and Aron 1986; Diamond 2003; Regan and Berscheid 1995; Rubin 1970). According to Fisher (1998) lust is governed by the sexual mating system, which is unrelated to bonding or long-term relationships, whereas love is governed by the pair-bonding system and attachment (Hazan and Shaver 1987; Hazan and Zeifman 1999). Such a distinction between love and lust enables mating without bonding or bonding without mating (Hazen and Zeifman 1994).

The critical difference between love and lust lies in the temporal perspective. Since it is associated with long-term goals of commitment and attachment, love promotes thoughts related to the future. Lust, on the other hand, relates to short-term goals of sexual desire and stimulates thoughts about the present moment. According to research on social cognition, when a person repeatedly experiences a particular way of thinking in a particular situation, even a subtle priming of such an experience can trigger that way of thinking (e.g. Li, Lu, \& Miller, 2013). Therefore, we anticipate that the priming of thoughts of love or lust would induce a different temporal focus, which would then affect subsequent behavior.

Based on the distinction between love and lust, previous studies explored the influence of the two emotions on information processing and decisions. The attitude and behavior to the relationship with a partner have been found to depend strategically on whether one sees the relationship either in a long-term perspective or in a short-term perspective (Jonason, Li, Webster, \& Schmitt, 2009). Förster, Epstude and Özelsel (2009) found the effects of love and lust on thinking styles. They suggested that individuals who are feeling love take on a long-term perspective, which leads to a holistic processing style and thereby enhances creative thinking. With sexual encounters, on the other hand, individuals focus on the present and details, which strengthens analytic thinking. Förster et al. (2009) explored various possible differences between people who are primed with love versus those who are primed with lust, and the only difference they found was a difference in temporal perspective. Participants primed with love reported more wishes, goals, or events that related to future events compared to participants primed with sexual desire. Förster et al. (2010) also found similar results in processing styles. They showed that love induces a long-term perspective which in turn stimulates global processing, while lust induces a short-term perspective which in turn triggers local processing. These differences in processing styles influenced participants' partnership evaluation. Van den Bergh, Dewitte, and Warlop (2008) also argued that the priming of sexual desire prompts the nerve system associated with satisfying an instinctive desire, makes individuals more sensitive to short- 
term rewards, and leads to a short-sighted perspective even in different areas from which the stimulation started.

Thus, we predict that consumers who are primed with love will show higher preferences for products that provide benefits in the long term rather than the short term. In other words, considering that many products accompany a trade-off between short-term gratification and long-term benefits, each customer may be sensitive to short-term gratification, or on the contrary, may put an emphasis on long-term advantages. In this case, consumers who are primed with love, which is characterized by continuous commitment and sharing one's life over a long period, will adopt a long-term perspective and will ultimately prefer goods that generate long-term value. Meanwhile, consumers who are primed with lust will take a short-term perspective and will show a preference toward products with minimal short-term loss or with immediate benefits. Consequently, we suggest the following hypothesis:

Hypothesis 1: Customers who are primed with feelings of love will be more likely to prefer products that have long-term benefits than those who are primed with feelings of lust.

\subsection{Love, Lust and Risk-Taking Decisions}

Most people wish to avoid danger (Scholer et al. 2010). The reason decision-making is not easy is because it often involves risk factors. Selecting a relatively risky alternative to obtain benefit is called risk-taking decision-making, and choosing a safe alternative by giving up benefits or opportunities is called risk-avoidance decisionmaking (Chung, Kim, and Son 2011).

Risk-taking behaviors regarding sexual activity include not using a condom, having many sexual partners and having intercourse with a person who engages in sexual activity with many people (Lock, Ferguson, and Wise 1998; Naom, 1993). Love is accompanied with long-term bonding, attachment and commitment toward a specific target while lust can be expressed in extreme behaviors, such as one-night stands to satisfy sexual desires (Sprecher and Regan 1998). Hence, lust inevitably accompanies a higher level of risk (e.g., AIDS) than love.

The risk-taking tendency varies, depending on the extent to which one is interested in the future or the present moment. Research has shown that how people envisions their present and future influence likelihood of engaging in high-risk activities (Rothspan and Read 1996). More specifically, people who focus on immediate concerns and pleasures and who are unable to comprehend how their current actions will affect them in the future may be more likely to take risks. In contrast, people who are oriented toward future oriented tend to have more well-developed visions of their future, possess goals that can be achieved in the future, and are more likely to possess an awareness of the 
contingency between their current actions and their future outcomes (DeVolder \& Lens, 1982; Markus \& Ruvolo, 1989), which will reduce the likelihood of engaging in risk behaviors. In other words, those who make decisions based on the long-term perspective will consider consequences in the future more than gratification in the present moment. Furthermore, if a certain action is expected or is able to create negative consequences, one's intention to participate in that action will significantly decrease in order to avoid future risks. On the other hand, consumers who make decisions based on a shortterm perspective will care less about the future, but will react more sensitively to the possible benefits in the present. Therefore, satisfaction one can experience from a specific action in the present moment will make the person insensitive to negative consequence they might experience in the future. In other words, a short term perspective can lead to higher risk-taking. For example, although excessive drinking has the favorable effect of temporary stress relief or refreshment, it is considered as risky as it leads to long-term harm with respect to one's health. Thus, a consumer who looks at risky actions in the long-term perspective will be less likely to participate in those actions, while a consumer who looks at such actions in a shortterm perspective will highly evaluate the immediate gratification and overlook the negative consequences, leading to a higher intention to participate in risky activities. Considering that feelings of love is lined to thoughts related to a long-term perspective whereas feelings of lust is associated with thought related to a short-term perspective, it is expected that compared to consumers who are primed with love, consumers who are primed with sexual desire are more likely to participate in risky behavior. Thus, we developed the following hypothesis:

Hypothesis 2: Consumers who are primed with lust are more likely to participate in risky behavior than those who are primed with love.

\section{Study 1}

The purpose of Study 1 was to test our hypothesis: whether consumers are more likely to prefer a product providing long-term benefits when they are primed with feelings of love versus lust. We selected a hybrid car as the product with long-term benefits. Although in the short-term perspective, initial costs of purchasing hybrid cars are usually higher than other cars, this type of cars could provide long-term benefits: hybrid cars help protect the environment and their fuel efficiencies are better than other cars. We expected that participants who are primed with feelings of love would be more favorable toward a hybrid car than those who are primed with feelings of lust.

The Influence of Love versus Lust on Consumer Judgments 


\subsection{Sample and Procedure}

A total of 64 undergraduate students (29 females; $M_{\text {age }}=22.2$ years) participated in this study, in exchange for extra course credit. Participants were randomly assigned to one of the two conditions: love versus lust. The experiment was conducted as part of a series of studies.

First, participants came to the lab and were asked to carefully watch a short video. We used a love-making scene from the movie, "What More Do I Want”, which was released in 2010. Participants were then given background information about the movie in a written instruction, as follows: "Now, you are going to see a portion of a movie which was recently filmed in Italy. The dubbing of the dialogue in Korean has not been completed, so you will see a version of the film without a soundtrack." The general instruction was followed by differential explanations intended to prime love versus lust, which were adapted from Fisher and Byrne (1978). The explanation for the video in the love condition was as follows:

The man and woman in the movie were a campus couple envied by everyone during their university years and through their continued dating, even after graduation. They have recently made plans to be married. This scene is about a man and woman who are on a trip together during the weekend to enjoy good food. Later they returned to their hotel room after the meal, and are showing affection toward each other.
The explanation for the video in the lust condition was as follows:

The man and woman in the movie are open to sex, and they have agreed to enjoy a one- night stand that evening after their eyes met while dancing in the club. This scene is about a man and woman enjoying sexual intercourse at a motel near the club with the sole purpose of enjoying intercourse, without any emotion of love.

Then, participants watched a portion of the movie that was approximately three minutes long. The film depicted a heterosexual interaction in which both partners undressed and engaged in heavy petting. After watching the video, participants were asked to rate the relationship between the man and the woman in the video for manipulation check. They were asked to indicate the degree of agreement with the following statements: "the couple is in romantic love; the film depicts a lasting love; the couple is in a long-term relationship" ( 1 = strongly disagree, 7 = strongly agree; Cronbach $a=.95)$. Then, participants proceeded to a seemingly unrelated second study. They were told that the purpose of the second study was to investigate consumers' attitudes toward hybrid cars. We showed them an article about hybrid cars. The article included an explanation that hybrid cars' initial purchase cost was about 20\% more expensive than other cars, but their fuel efficiencies were higher, so people could save up to $20 \%$ in fuel costs. Then, participants were 
asked to indicate their attitudes toward hybrid cars on seven-point scales: "I have a good feeling toward hybrid cars," and "Hybrid cars are appealing to my taste” $(a=.93)$. Finally, participants were debriefed and thanked.

\subsection{Results}

Manipulation Check. We checked whether our manipulation was successful. As expected, it was confirmed that the participants in the love condition were more likely to experience feelings of love than those in the lust condition $\left(\mathrm{M}_{\text {love }}=4.53, \mathrm{SD}=1.28\right.$ vs. $\mathrm{M}_{\text {lust }}=2.80, \mathrm{SD}$ $=1.56 ; \mathrm{F}(1,62)=23.34, \mathrm{p}<.001)$. Thus, our manipulations were deemed as successful.

\subsubsection{Attitudes toward Hybrid Cars}

We assessed whether feelings of love versus lust affected participants' attitudes toward hybrid cars. A one-way ANOVA run on attitudes toward hybrid cars yielded a significant effect $(F(1,62)=4.60, p<.05)$. Participants in the love condition were more likely to prefer hybrid cars than those in the lust condition $\left(M_{\text {love }}=5.65, S D=.86\right.$ vs. $M_{\text {lust }}=5.13, S D$ $=1.03)$. Thus, Hypothesis 1 was supported.

The results of Study 1 demonstrate that consumers were more likely to prefer a product providing a long-term perspective when experiencing feelings of love versus lust. In the next study, we examine whether feelings of love versus lust affect consumers' risk-taking behaviors.

\section{Study 2}

The purpose of Study 2 was to investigate whether consumers who are primed with feelings of lust take more risk than those who are primed with feelings of love. Participants were asked to imagine a situation in which they had an opportunity to take a free trip to an area with danger. We predicted that participants who are primed with feelings of lust would be more willing to take the risk of going on a trip with danger than those who are primed with feelings of love.

\subsection{Sample and Procedure}

Eighty-seven undergraduate students (50 $\mathrm{fe}^{-}$ males; $\mathrm{M}_{\mathrm{age}}=21.7$ years) participated in exchange for extra course credit. Participants were randomly assigned to one of the two conditions (love vs. lust). Participants were told they were going to participate in several unrelated studies.

Participants came to the lab and were asked to carefully watch a short video. The procedures of this study were similar to those of Study 1. After watching the video, participants were asked to respond to the questionnaires about the relationship between the man and the woman in the 
video. We used the same scales as in Study 1 $(a=.95)$.

After responding to the questionnaires, all participants were given the same hypothetical scenario in which they were considering going on a free trip; however, they were informed that the destination had a high risk of possible volcanic eruption. After reading the scenario, they reported their intention to go on the trip, using seven-point scales: "I would like to take this trip," "I would like to accept this offer," "It is a good idea to go on this trip," and "Visiting the area would be wonderful" $(a=.91)$.

\subsection{Results}

\subsubsection{Manipulation Check}

We performed a one-way ANOVA to confirm whether the explanation for the video induced feelings of love or lust, depending on the experimental condition. As a result, participants in the love condition experienced more feelings of love than those in the lust condition ( $M_{\text {love }}=$ 4.69, $S D=1.15$ vs. $M_{\text {lust }}=2.56, S D=1.27$; $F(1,85)=66.51, p<.001)$. Thus, our manipulation was successful.

\subsubsection{Tendency to Take Risks}

An ANOVA, with the tendency to take risks as the dependent variable and feelings of love versus lust as the independent variable, yielded a significant effect $(F(1,85)=6.31, p<.05)$. The results showed that participants who experienced feelings of lust took more risks than those who experienced feelings of love when they engaged in decision-making ( $M_{\text {love }}=3.36$, $S D=1.52$ vs. $\left.M_{\text {ust }}=4.25, S D=1.75\right)$. Thus, hypothesis 2 was also supported.

\section{Conclusion}

We investigated the impacts of love and lust, which are among the most instinctive emotions, on consumer behavior. Love is related to thoughts in the long-term perspective and accompanied by emotional bonding, attachment and commitment while lust is associated with thought in the short-term perspective and accompanied by desire to engage in sexual activities (Förster et al. 2010). Based on this distinction, we hypothesized that consumers who are primed with love are more likely to have preference toward products providing long-term benefits, compared to consumers who are primed with sexual desires. Also, considering that feelings of lust tend to result in short-sighted behavior such as a one-night stand with a stranger (Sprecher and Regan 1998), we predicted that lust-primed individuals are more likely to engage in risky behavior than those who are primed with love. The current research conducted two experiments to test these hypotheses. Study 1 
examined the hypothesis that consumers who are primed with feelings of love would be more favorable toward products with long-term value than consumers who are primed with feelings of lust. The results showed that the consumers who were primed with feelings of love displayed a greater preference toward hybrid cars, which provide long-term values, than the consumers who were manipulated by feelings of lust. In Study 2, we examined the hypothesis that the consumers who are primed with feelings of lust are more likely to take risk than those primed with love. We found that consumers who were manipulated by feelings of lust tended to make riskier decisions than those who were manipulated by feelings of love. Risky decision in Study 2 was taking a free trip to volcanic area, which is an appealing offer but involves risk.

By investigating the influence of feeling of love and lust on consumer behavior, the current research contributes to the literature on emotions, decision making, and risk-taking. The majority of research on risk taking has focused on the impact of cognitive factors on risk taking. The current research provides a better understanding of consumer risk taking by including emotional factors. Also, our findings provide managerial implications. Our research suggests that the effectiveness of marketing campaigns can differ depending on the fit between the product and the emotion they are attempting to induce. Specifically, a marketing message stimulating feelings of love would be beneficial for products with a long-term benefit such as a hybrid car, whilst the message stirring up feelings of lust would have a bigger effect on products with immediate gratification. On the other hand, if a product or service involves risks, promoting feeling of lust (vs. love) would be more effective in increasing consumers' purchase intention.

Our research suggested that feeling of love can lead to preference for long-term benefits (vs. short-term gratification) and risk aversion. Though it is predicted that the reason why love and lust influence such behavioral tendencies is due to the difference in temporal perspectives induced by these emotions, this assertion was not directly verified by empirical tests. Also, since we did not include control groups in our studies, we cannot conclude whether the effect was driven by feeling of love or lust. Therefore, future research is needed to directly investigate the underlying mechanism.

The findings of the present research suggest directions for future research. People feel love toward a specific target individual whereas sexual desire can be fulfilled with a relatively unfamiliar individual. Assuming such distinction between love and lust, people who are primed with love might be more favorable toward innovative products than those who are primed with love. Also, several studies based on construal-level theory have shown that the process of decisionmaking and persuasion vary depending on tem- 
poral distance (e.g. Trope and Liberman, 2003). Based on the differential temporal perspectives of love and lust, future research can further examine the effects of love and lust on processing styles in more various domains.

〈Received September 8. 2016〉

$\langle$ Revised October 20. 2016〉

〈Accepted October 26. 2016〉

\section{References}

Aron, Arthur, and Elaine N. Aron (1986), Love and the Expansion of the Self: Understanding Attraction and Satisfaction. New York: Hemisphere.

Buss, David M., and David P. Schmitt (1993), "Sexual Strategies Theory: An Evolutionary Perspective on Human Mating," Psychological Review, 100 (April), 204-232.

Cacioppo, Stephanie, Francesco Bianchi-Demicheli, Chris Frum, James G. Pfaus, and James W. Lewis (2012), “The Common Neural Bases between Sexual Desire and Love: A Multilevel Kernel Density fMRI Analysis," The Journal of Sexual Medicine, 9 (4), 1048-1054.

De Volder, Maurice L., and Willy Lens (1982), "Academic achievement and future time perspective as a cognitive - motivational concept." Journal of Personality and Social Psychology 42, no. 3, 566.
Diamond, Lisa M. (2003), "What Does Sexual Orientation Orient? A Biobehavioral Model Distinguishing Romantic Love and Sexual Desire," Psychological Review, 110 (January), 173-192.

Diamond, Lisa M. (2004), “Emerging Perspectives on Distinctions between Romantic Love and Sexual Desire," Current Directions in Psychological Science, 13 (June), 116-119.

Epstude, Kai, and Jens Förster (2011), “Seeing Love, or Seeing Lust: How People Interpret Ambiguous Romantic Situations," Journal of Experimental Social Psychology, 47 (September), 1017-1020.

Fisher, Helen E. (1998), "Lust, Attraction, and Attachment in Mammalian Reproduction," Human Nature, 9 (March), 23-52.

Fisher, William. A., and Donn Byrne (1978), "Sex Differences in Response to Erotica? Love versus Lust," Journal of Personality and Social Psychology, 36 (February), 117125.

Förster, Jens, Amina Özelsel, and Kai Epstude, (2010), “How Love and Lust Change People's Perception of Relationship Partners," Journal of Experimental Social Psychology, 46 (March), 237-246.

Goldberg, Lewis R. (1999), “A Broad-Bandwidth, Public-Domain, Personality Inventory Measuring the Lower-Level Facets of Several Five-Factor Models," In Mervielde, I., I. J. Deary, F. De Fruyt, and F. Ostendorf (Eds.), Personality Psychology in Europe (Vol. 7, 
pp. 7-28). Tilburg, The Netherlands: Tilburg University Press.

Goldsmith, Ronald E., and Stephen J. Newell (1997), "Innovativeness and Price Sensitivity: Managerial, Theoretical, and Methodological Issues," Journal of Product and Management, 6 (3), 163-174.

Harlow, W. V., and Keith C. Brown (1990), The Role of Risk Tolerance in the Asset Allocation Process: A New Perspective. Research Foundation of the Institute of Chartered Financial Analysis, Virginia: Charlottesville.

Hazan, Cindy, and Phillip Shaver (1987), "Romantic Love Conceptualized as an Attachment Process," Journal of Personality and Social Psychology, 52 (March), 511-524.

Hazan, Cindy, and Debra Zeifman (1994), "Sex and the Psychological Tether," In Kim Bartholomew and Daniel Perlman (Eds.), Advances in Personal Relationships (Vol. 5, pp. 17-52). London: Jessica Kingsley.

Hazan, Cindy, and Debra Zeifman (1999), "Pair Bonds as Attachments: Evaluating the Evidence," In Jude Cassidy and Phillip Shaver (Eds.), Handbook of Attachment: Theory, Research, and Clinical Applications (pp. 336-354). New York: Guilford Press. Lock, Sharon E., Stephanie L. Ferguson, and Carl Wise (1998), "Communication of Sexual Risk Behavior among Late Adolescents," Western Journal of Nursing Research, 20 (June), 273-294.
Markus, H., \& Ruvolo, A. (1989), Possible selves: Personalized representations of goals. In L. Pervin (Ed.), Goal concepts in personality and social psychology. Hillsdale, NJ: Erlbaum, 211-241

Mikulincer, Mario (1998), “Attachment Working Models and the Sense of Trust: An Exploration of Interaction Goals and Affect Regulation," Journal of Personality and Social Psychology, 74 (May), 1209-1224.

Mikulincer, Mario, and Phillip Shaver (2007), Attachment in Adulthood: Structure, Dynamics, and Change. New York: Guilford Press.

Naomi, Seboni M. (1993), Botswana Female Youth: Perception of Sexuality and RiskTaking Behaviors. Doctoral Dissertation. University of California: San Francisco.

Nicholson, Nigel, Emma Soane, Mark FentonO'Creevy, and Paul Willman (2005), "Personality and Domain-Specific Risk Taking," Journal of Risk Research, 8 (2), 157-176.

Regan, Pamela C., and Ellen Berscheid (1995), "Gender Differences in Beliefs about the Causes of Male and Female Desire," Personal Relationships, 2 (December), 345-358.

Rothspan, S., \& Read, S. J. (1996), "Present versus future time perspective and HIV risk among heterosexual college students," Health Psychology, 15(2), 131.

Rubin, Zick (1970), "Measurement of Romantic Love," Journal of Personality and Social Psychology, 16 (October), 265-273. 
Scholer, Abigail A., Xi Zou, Kentaro Fujita, Steven J. Stroessner, and E. Tory Higgins (2010), "When Risk-Seeking Becomes a Motivational Necessity," Journal of Personality and Social Psychology, 99 (August), 215231.

Sprecher, Susan, and Pamela C. Regan (1998), "Passionate and Companionate Love in Courting and Young Married Couples," Sociological Inquiry, 68 (April), 163-185.
Trope, Yacov, and Nira Liberman (2003), "Temporal Construal," Psychological Review, 110 (3), 403-421.

Wulfert, Edelgard, Choi K. Wan, and Cheryl A. Backus (1999), "Gay Men's Safer Sex Behavior: An Integration of Three Models," Journal of Behavioral Medicine, 19 (August), 345-366.

Zuckerman, Mavin (1983), "Sensation Seeking and Sports," Personality and Individual Differences, 4 (3), 285-293. 